\title{
Optimization of Indoor Thermal Comfort Parameters with the Adaptive Network-Based Fuzzy Inference System and Particle Swarm Optimization Algorithm
}

\author{
Jing Li, ${ }^{1}$ Shao-Wu Yin, ${ }^{1,2}$ Guang-Si Shi, ${ }^{3}$ and Li Wang ${ }^{1,2}$ \\ ${ }^{1}$ School of Energy and Environmental Engineering, University of Science \& Technology Beijing, Beijing 100083, China \\ ${ }^{2}$ Beijing Key Laboratory of Energy Saving and Emission Reduction for Metallurgical Industry, \\ University of Science and Technology Beijing, Beijing 100083, China \\ ${ }^{3}$ School of Mechanical Engineering, University of Science \& Technology Beijing, Beijing 100083, China
}

Correspondence should be addressed to Shao-Wu Yin; yinsw@ustb.edu.cn

Received 1 December 2016; Revised 21 February 2017; Accepted 26 February 2017; Published 22 March 2017

Academic Editor: Alessandro Lo Schiavo

Copyright (C) 2017 Jing Li et al. This is an open access article distributed under the Creative Commons Attribution License, which permits unrestricted use, distribution, and reproduction in any medium, provided the original work is properly cited.

\begin{abstract}
The goal of this study is to improve thermal comfort and indoor air quality with the adaptive network-based fuzzy inference system (ANFIS) model and improved particle swarm optimization (PSO) algorithm. A method to optimize air conditioning parameters and installation distance is proposed. The methodology is demonstrated through a prototype case, which corresponds to a typical laboratory in colleges and universities. A laboratory model is established, and simulated flow field information is obtained with the CFD software. Subsequently, the ANFIS model is employed instead of the CFD model to predict indoor flow parameters, and the CFD database is utilized to train ANN input-output "metamodels" for the subsequent optimization. With the improved PSO algorithm and the stratified sequence method, the objective functions are optimized. The functions comprise PMV, PPD, and mean age of air. The optimal installation distance is determined with the hemisphere model. Results show that most of the staff obtain a satisfactory degree of thermal comfort and that the proposed method can significantly reduce the cost of building an experimental device. The proposed methodology can be used to determine appropriate air supply parameters and air conditioner installation position for a pleasant and healthy indoor environment.
\end{abstract}

\section{Introduction}

The quality of the indoor air environment in offices is related to the comfort and health of people and affects the work efficiency of people. Strong local blowing, poor air circulation, and odors exist in an air-conditioned room. Furthermore, the long-term existence of air pollutants in the human body exerts a pernicious effect on people's health. According to the definition of "healthy" by the World Health Organization, mental and physical aspects should be promoted by having healthy indoor air and a safe, healthy, comfortable indoor environment; these two are the fundamental purposes of modern architecture [1]. Therefore, the problem of evaluating and improving indoor environment quality should be solved immediately.

The heating ventilation air conditioning (HVAC) design for modern indoor settings is based only on temperature, air velocity, and relative humidity. However, an individual's perceptions of the environment cannot be exactly reflected by these three indicators. Predicted mean vote (PMV), predicted percentage of dissatisfied people (PPD), and mean age of air are generally utilized as evaluation indicators in the design of HVAC, but they are not used as design indicators to guide the design process of HVAC. The installation location of an air conditioner and air supply parameters are designed based on experience and can be amended according to evaluation indicators. However, this method involves much workload and is suboptimal. These controllable parameters required to achieve optimal results were directly considered in this study.

The most common and accurate means to predict indoor air movement is the use of computational fluid dynamics (CFD) models [2]. Many studies have investigated CFD applications, particularly the flow and heat transfer. The lattice 
Boltzmann method, which is utilized for the numerical simulation of flow and heat transfer, was used to study the convection heat transfer of nanofluids in an enclosure by Karimipour et al. [3-7]. The CFD model was used by Skovgaard and Nielsen [8] to simulate indoor air flow, and CFD technology was adopted in air conditioning engineering. However, the model grid was divided into thousands of millions. Therefore, this method is highly complicated in terms of calculation, and the real-time capability is insufficient. To solve this problem, several simplified models [9-11] have been proposed, but the accuracy of these simplified models is worse than that of the CFD model; furthermore, making a dynamic prediction of the thermal environment is difficult [12]. Although the analysis of CFD provides a near-optimal solution, the analysis of CFD parameters is not continuous.

As practical tools, mathematical metamodels can convert the discretized domain into a continuous one, and this conversion improves the accuracy of the near-optimal solution without the need for excessive computational power. Artificial neural networks (ANN) have been successfully used to develop such metamodeling relationships between design and objective variables. For example, Krauss et al. [13] used the velocity coefficient as the thermal comfort indicator and discussed the influence of CFD-ANN coupling on the interior design; the computation time was reduced considerably. The backpropagation (BP) neural network model was used by $\mathrm{Xu}$ et al. [14] to replace the CFD model in the simulation of indoor air flow. Generally, ANN cannot directly deal with the knowledge structure, although it has a strong selflearning ability. Stvrakakis et al. [15] presented a novel CFDANN computational method to optimize window sizes for thermal comfort in ventilated buildings; the novel method uses the radial basis function (RBF) architecture. Although the methodology is useful for architects, the algorithm has its limitations. By referring to previous studies, the fuzzy system and ANN were combined in this study, and an adaptive neural fuzzy inference system (ANFIS) [16] was established. The proposed methodology adopts a CFD-ANFIS coupling procedure to correlate the input and output variables. The simulation results showed that the fitting accuracy and training speed of the metamodel improved significantly.

To optimize the solution function, Sun et al. [17] used the genetic algorithm to develop indoor thermal comfort parameters and found that the indoor air quality improved after optimization. Luan and $\mathrm{Lu}$ [18], who used the adaptive genetic algorithm to optimize the neural network, also obtained a good experimental result. However, the genetic algorithm cannot solve the problem of large-scale computation because of its complex calculation method and low rate of convergence. Therefore, the algorithm is inclined to result in premature convergence. To improve optimization speed without any loss in precision, the improved particle swarm optimization (PSO) algorithm was employed in this study. The global searching strategy of the population was retained in the improved PSO algorithm to avoid complex genetic operations, such as coding, crossover, and mutation. Thus, the algorithm is simplified and easy to implement.

In previous research on indoor environment indicators, PMV [19], PPD [20], and age of air [21] were widely used as
TABLE 1: PMV indicator values.

\begin{tabular}{lccccccc}
\hline $\begin{array}{l}\text { Thermal } \\
\text { sensation }\end{array}$ & Hot & Warm & $\begin{array}{l}\text { Micro } \\
\text { warm }\end{array}$ & Moderate & $\begin{array}{c}\text { Micro } \\
\text { cool }\end{array}$ & Cool & Cold \\
\hline PMV & +3 & +2 & +1 & 0 & -1 & -2 & -3 \\
\hline
\end{tabular}

thermal comfort indicators. In this study, a physical laboratory model was established with the CFD software. Indoor air temperature, air velocity, radiation temperature, and relative humidity as well as the distance between the air supply outlet and the sampling point were obtained through a CFD simulation. The database in CFD was adopted to train ANN. Subsequently, the objective functions of the PSO algorithm were established; these functions comprised PMV, PPD, and age of air [22-24]. Optimization of the objective functions was then conducted with the stratified sequence method [25, 26], and the optimal values of the parameters were obtained. Overall, the proposed methodology meets the requirements of indoor thermal comfort and provides a reference for the design and improvement of indoor air conditioning systems [27].

\section{Evaluation Indicators for the Indoor Thermal Comfort Environment}

2.1. Age of Air. The mean age of air refers to the amount of time air has been in a room; it involves the ability to exclude pollutants. Generally, when indoor pollutant sources are distributed uniformly and a room receives fresh air, the mean age of air is small, the air quality is good, and the ability to remove pollutants is strong. As indicated by its physical meaning, the mean age of air is a significant indicator to measure the freshness degree of air and the exchange of air in an air-conditioned room.

2.2. Thermal Comfort Indices. The PMV indicator was developed by Professor P. O. Fanger. PMV indicates the thermal response of humans. The PMV indicator adopts seven degrees [29], as shown in Table 1.

The feelings of most people in the same environment can be represented by the PMV indicator. Thus, the indicator is utilized to evaluate whether a thermal environment is comfortable or not. However, due to individual differences, the PMV indicator cannot represent all personal feelings. Therefore, PPD was proposed to indicate the percentage of people who are dissatisfied with a given thermal environment.

\subsection{Indoor Air Parameters}

2.3.1. Air Velocity. In a thermal environment, air flow provides fresh air to humans and speeds up the human body's convective heat and evaporative cooling to a certain extent [30].

2.3.2. Body Temperature. Temperature is the main factor that affects thermal comfort because it affects the human body directly through convection and radiation heat exchange. 


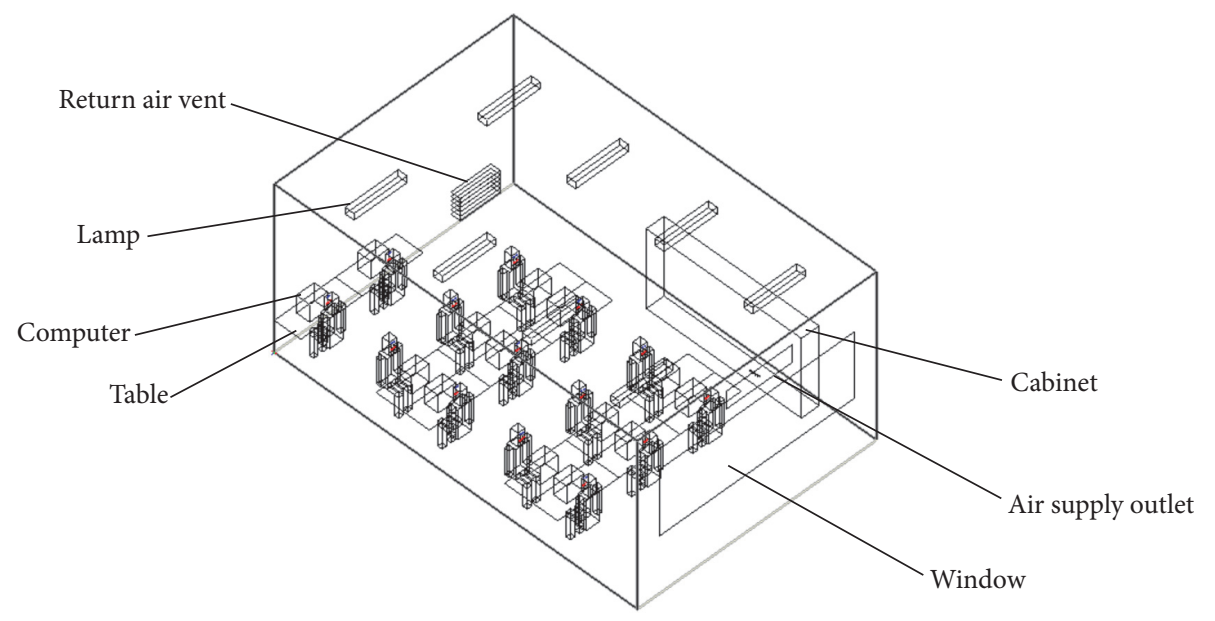

FIGURe 1: Physical laboratory model.

In this study, body temperature was used as an indicator. Bedford [31] found that the human body is highly sensitive to temperature, and the ability to reproduce the sensation of cold and hot is not lower than the reproducibility of the physiological reaction of the organism.

2.3.3. Radiation Temperature. Average radiation temperature is influenced by surface temperature. Generally, the average radiation temperature is not always uniform in the actual production and living environment. Moreover, people often feel cold or hot in a certain part of the body. Thus, studying the influence of the deviation of the average radiation temperature from the air temperature and the effect of the asymmetry of heating or cooling on the physiological or sensory responses of the human body is important.

2.3.4. Relative Humidity. The influence of environmental humidity on the thermal comfort of the human body is mainly manifested in the effect of heat loss from the skin to the environment. Research shows that less than $30 \%$ humidity causes an unsatisfactory thermal sensation and affects indoor air quality [32].

\section{Modeling}

3.1. CFD Modeling. With previous models as a basis, a typical laboratory model was established according to the characteristics of a university laboratory. The physical model is shown in Figure 1. The size of the model was $8.2 \mathrm{~m} \times$ $5.4 \mathrm{~m} \times 3.8 \mathrm{~m}$, and the laboratory was enclosed in a standalone building complex that included 14 seated people and typical equipment, such as a window $(4.4 \mathrm{~m} \times 1.5 \mathrm{~m})$, a file cabinet $(1.8 \mathrm{~m} \times 0.4 \mathrm{~m} \times 3.5 \mathrm{~m}), 8$ lamps $(50 \mathrm{~W})$, and 14 desks. In addition, a computer emitting $200 \mathrm{~W}$ of heat was placed on each desk. People with an average height of $1.73 \mathrm{~m}$ were assumed to remain seated in front of the computers and release heat of $58.2 \mathrm{~W} / \mathrm{m}^{2}$.

The air supply outlet of the model (size of $0.9 \mathrm{~m} \times 0.5 \mathrm{~m}$ ) was above the window on the rear wall, and the return air vent was on the opposite wall. The air supply's temperature and velocity were $19^{\circ} \mathrm{C}$ and $0.75 \mathrm{~m} / \mathrm{s}$, respectively. The initial relative humidity in the room was $60 \%$.

To simplify the research problem, several assumptions were adopted [33]. First, indoor air cannot be compressed and is in line with the Boussinesq hypothesis. Second, indoor air exhibits a steady flow. Third, the thermal radiation between the solid walls and objects is disregarded. Fourth, indoor air is conducive for transparent radiation media. Lastly, the influence of air leakage is disregarded.

Under these assumptions, the governing equations are satisfied in general form as follows:

$$
\frac{\partial(\rho \phi)}{\partial t}+\operatorname{div}(\rho u \phi)=\operatorname{div}(\Gamma \operatorname{grad} \phi)+s,
$$

where $\phi$ is a general variable, $\Gamma$ is the generalized diffusion coefficient, and $s$ is the generalized source term.

The CFD software was used to establish the laboratory model. A hexahedral mesh grid was utilized, and the CFD model was simulated. A total of 1000 datasets from the model were obtained when the CFD model was calculated to converge. The data were obtained from the height of the human chest ( $X Z$ section of $Y=1.1 \mathrm{~m}$ height), and $D$ represents the distance from the sampling point to the air supply outlet. Some of the data are illustrated in Table 2.

The distributions of indoor thermal comfort indicators PMV, PPD, and mean age of air were obtained with a postprocessing software and are shown in Figures 2-4, respectively.

The smallest values of PMV were around -1.5 in the seat near the air supply outlet of the air conditioner, as depicted in Figure 2. The largest PMV values were about 0.6 in the upper left corner of Figure 2. With regard to people's comfort, the values of PMV were between -1.5 and -1 in the seat near the air supply outlet, and people in this indoor setting have an obvious feeling of coldness. The values of PMV were between -0.5 and 0.5 in the seat near the return air vent, and people here have a feeling of "moderate" hotness and coldness. In the middle seats of the room, the values of PMV were between -1 and 0.2 , and the feeling of thermal discomfort was obvious. Overall, the distribution of PMV 
TABLE 2: Indoor parameters.

\begin{tabular}{|c|c|c|c|c|c|c|c|c|}
\hline Code & $\begin{array}{c}\text { Indoor } \\
\text { temperature } \\
T\left({ }^{\circ} \mathrm{C}\right)\end{array}$ & $\begin{array}{l}\text { Current Speed } \\
V(\mathrm{~m} / \mathrm{s})\end{array}$ & $\begin{array}{l}\text { Distance } \\
D(\mathrm{~m})\end{array}$ & $\begin{array}{c}\text { Radiant temperature } \\
\operatorname{Tr}\left({ }^{\circ} \mathrm{C}\right)\end{array}$ & $\begin{array}{l}\text { Relative humidity } \\
w(\%)\end{array}$ & PMV & PPD & $\begin{array}{l}\text { Age of air } \\
\text { (s) }\end{array}$ \\
\hline 1 & 22.98 & 0.26 & 2.21 & 20.32 & 49.93 & -0.84 & 20.04 & 128.97 \\
\hline 2 & 23.01 & 0.32 & 2.33 & 20.18 & 50.19 & -0.95 & 24.06 & 122.98 \\
\hline 3 & 22.38 & 0 & 2.51 & 21.14 & 51.05 & -0.38 & 8.07 & 137.11 \\
\hline 4 & 23.14 & 0.16 & 2.60 & 20.43 & 51.38 & -0.60 & 12.67 & 137.37 \\
\hline 5 & 22.71 & 0.22 & 2.76 & 20.28 & 51.29 & -0.79 & 18.30 & 124.19 \\
\hline$\ldots$ & $\ldots$ & $\ldots$ & $\ldots$ & $\ldots$ & $\ldots$ & $\ldots$ & $\ldots$ & $\ldots$ \\
\hline 997 & 22.63 & 0.22 & 6.50 & 21.62 & 53.91 & -0.41 & 8.59 & 189.68 \\
\hline 998 & 24.92 & 0.12 & 7.81 & 22.72 & 56.06 & -0.10 & 7.12 & 186.41 \\
\hline 999 & 24.91 & 0.09 & 8.62 & 20.76 & 57.48 & -0.13 & 5.38 & 137.34 \\
\hline 1000 & 24.15 & 0 & 8.82 & 22.47 & 53.23 & 0.01 & 5.00 & 161.24 \\
\hline
\end{tabular}
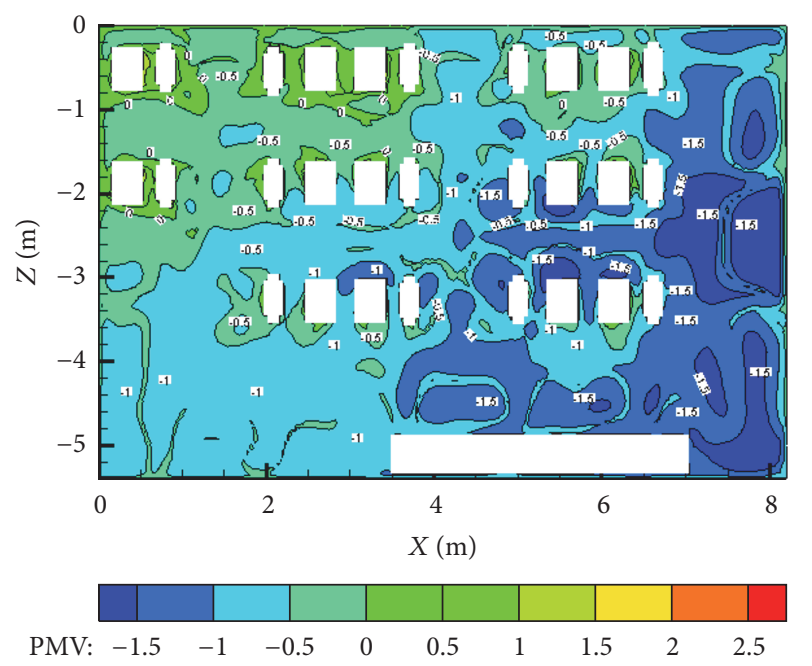

FIgURE 2: Distribution of PMV.

values was uneven. The farther a location was from the air supply outlet, the greater the values of PMV were. The largest difference in the distribution of PMV values was obtained in the middle seats.

As shown in Figure 3, the largest values of PPD were around $80 \%$ in the seat near the air supply outlet of the air conditioner. The smallest PPD values were about $10 \%$ in the upper left corner of Figure 3. In terms of the degree of people's satisfaction, the distribution of PPD values was uneven around the seat near the air supply outlet. The PPD values in the lower right corner of Figure 3 range from $50 \%$ to 75 . Several indoor persons exhibited symptoms of maladjustment, and the rate of dissatisfaction was high. The PPD values were between $10 \%$ and $15 \%$ (upper right corner of Figure 3), which means that most indoor persons felt good and were highly satisfied with the environment. The PPD values were between $15 \%$ and $25 \%$ in the seat near the return air vent; most persons felt generally satisfied. The PPD values were around $10 \%$ in the upper left corner of Figure 3, which indicates that the persons indoors were highly satisfied

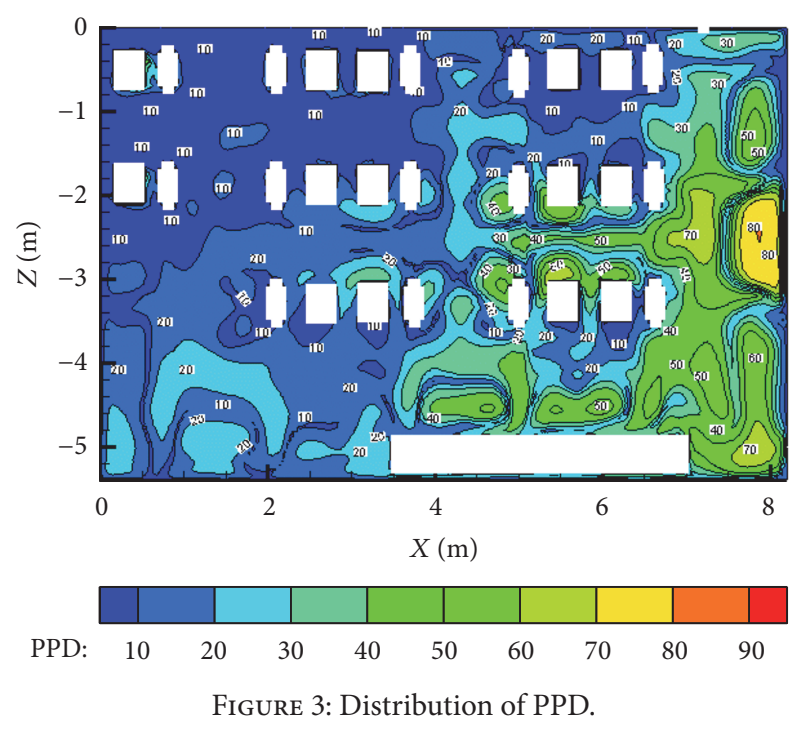

with the environment. The PPD values were between $10 \%$ and $20 \%$ in the middle seats of the room, and people here felt generally satisfied with the environment. In sum, the distribution of PPD values was uneven. In the seat near the air supply outlet, people demonstrated highest satisfaction with the environment, as shown in the upper left corner of Figure 3 where the PPD values are the largest; this location did not meet people's requirements for a thermally comfortable environment. The PPD values ranged from $10 \%$ to $15 \%$ in the middle part of the room, and these values produced satisfactory thermal sensations.

The distribution of the mean age of air in the room is presented in Figure 4. The values of air age were between 20 and $60 \mathrm{~s}$ in the seat near the air supply outlet of the air conditioner. The values of air age are $220 \mathrm{~s}$ in the upper left corner of Figure 4 and are the largest values of air age. The analysis of the people's feelings toward the freshness degree of indoor air showed that people felt more comfortable with the air flow in the seat near the air supply outlet of the air conditioner. In the seat near the return air vent, the 

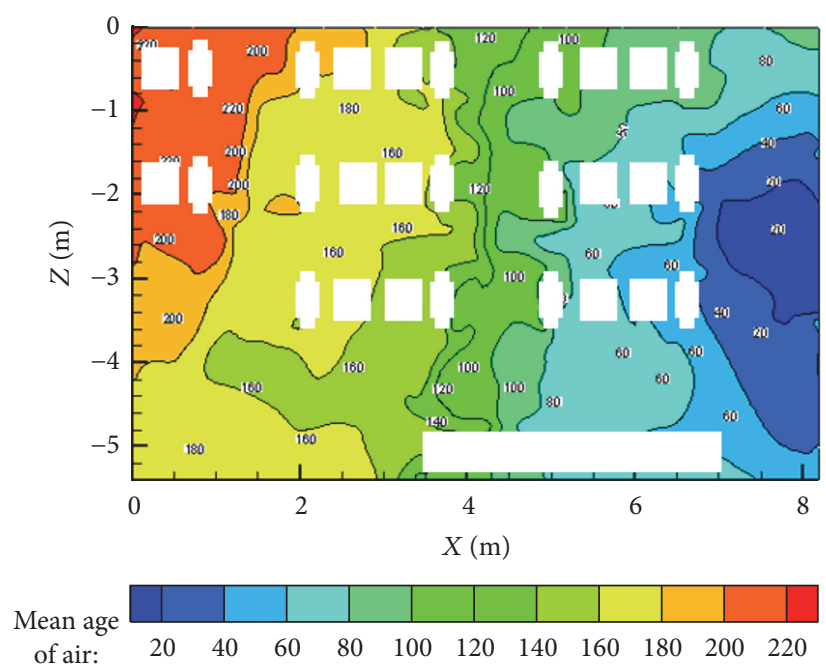

FIGURE 4: Distribution of the mean air age.

values of mean air age were around $220 \mathrm{~s}$, which indicate poor air circulation. The distribution of the mean age of air values was between 60 and $180 \mathrm{~s}$ in the middle seats of the room; here, people felt good air circulation. The greater the distance is from the air supply outlet to people, the greater the values of air age are. Overall, the whole tendency is gradually increasing.

As described in Table 2 and Figures 2-4, when the air supply outlet was arranged in accordance with the model above, the comfort requirements were not met. The distribution of the values of PMV, PPD, and age of air was uneven. The PPD values (Figure 3) were higher than the recommended upper limit $(10 \%)$ in space, which illustrated that people normally felt uncomfortable with the thermal environment. Therefore, optimizing the control parameters of the indoor air condition is necessary.

3.2. ANFIS Modeling. Both fuzzy logic and ANN were utilized in the architecture of ANFIS. ANFIS consisted of if-then rules and input-output pairs. ANFIS training was used to learn the algorithms of the neural network [34]. For simplicity, we assumed that the fuzzy inference system has five inputs $\left(x_{1}, x_{2}, x_{3}, x_{4}\right.$, and $\left.x_{5}\right)$ and one output $(f)$ under consideration. A typical rule set with base fuzzy if-then rules for a first-order Sugeno fuzzy model is presented in Figure 5.

The network structure consisted of three layers, namely, input, hidden, and output. The output data were PMV, PPD, and mean age of air. The number of neurons of the first hidden layer was 10 , and that in the second one was 32 . One thousand sets of input and output data were trained. The principles of the system are as follows.

The fuzzy rule according to Takagi-Sugeno is the linear combination of input variables.

$$
\mathbf{R}_{j} \text { : if } x_{1} \text { is } \mathbf{A}_{1}^{j} \text { and } x_{2} \text { is } \mathbf{A}_{2}^{j} \ldots \text { and } x_{n} \text { is } \mathbf{A}_{n}^{j} \text {, }
$$

then $y_{j}=p_{j 0}+p_{j 1} x_{1}+\cdots+p_{j n} x_{n}$, where $j=1,2, \ldots, m, m \leq$ $\prod_{i=1}^{n} m_{i}$.
For a given input $x$, the degree of adaptation to each rule can be obtained by using the fuzzy method of the single-point fuzzy set as follows:

$$
\alpha_{j}=\mu_{A_{1}^{j}}\left(x_{1}\right) \mu_{A_{2}^{j}}\left(x_{2}\right) \cdots \mu_{A_{n}^{j}}\left(x_{n}\right),
$$

where $\bar{\alpha}_{j}=\alpha_{j} / \sum_{i=1}^{m} \alpha_{i}$.

The architecture of the ANFIS used in this study is shown in Figure 5. The ANFIS architecture has five inputs and one output. This architecture is formed by using 5 layers and 75 if-then rules as follows.

Layer 1. Every node in this layer represents a linguistic variable with a node function as

$$
\mu_{i}^{j}=\mu_{A_{i}^{j}}\left(x_{i}\right),
$$

where $i=1,2, \ldots, n, j=1,2, \ldots, m_{i}$ and $N$ is the dimension of the input quantity. $m_{i}$ is the fuzzy partition number of $x_{i}$. $n=5$ and $m_{i}=3$, such that

$$
\mu_{i}^{j}=\exp \left(\left(-\frac{\left(x_{i}-c_{i j}\right)}{\left(\sigma_{i j}\right)}\right)^{2}\right),
$$

where $c_{i j}$ and $\sigma_{i j}$ comprise the parameter set and are referred to as premise parameters.

Layer 2. Each node in this layer is a circular node represented by II and multiplies the incoming signals and then sends the product out. For instance,

$$
\alpha_{j}=\mu_{1}^{i_{1}} \mu_{2}^{i_{2}} \cdots \mu_{n}^{i_{n}}
$$

where $i_{1} \in\left\{1,2, \ldots, m_{1}\right\}, i_{2} \in\left\{1,2, \ldots, m_{2}\right\}, \ldots, i_{n} \in\{1,2$, $\left.\ldots, m_{n}\right\}, j=1,2, \ldots, m, m=\prod_{i=1}^{n} m_{i}$.

Layer 3. Every node in this layer is a circular node expressed by $N$. The itch node calculates the ratio of the itch rules' firing strength to the sum of all rules' firing strengths as follows:

$$
\bar{\alpha}_{j}=\frac{\alpha_{j}}{\sum_{i=1}^{m} \alpha_{i}} .
$$

Layer 4. Each node $i$ in this layer is a square node with node function:

$$
\begin{aligned}
y_{i j}=p_{j 0}^{i}+p_{j 1}^{i} x_{1}+\cdots+ & p_{j n}^{i} x_{n}=\sum_{l=0}^{n} p_{j}^{i} x_{l} \\
& (j=1,2, \ldots, m ; i=1,2, \ldots, r) .
\end{aligned}
$$

Layer 5 . The single node in this layer is a circular node shown by $P$ that calculates the overall output as the summation of all incoming signals as follows:

$$
y_{i}=\sum_{j=1}^{m} \bar{\alpha}_{j} y_{i j}
$$




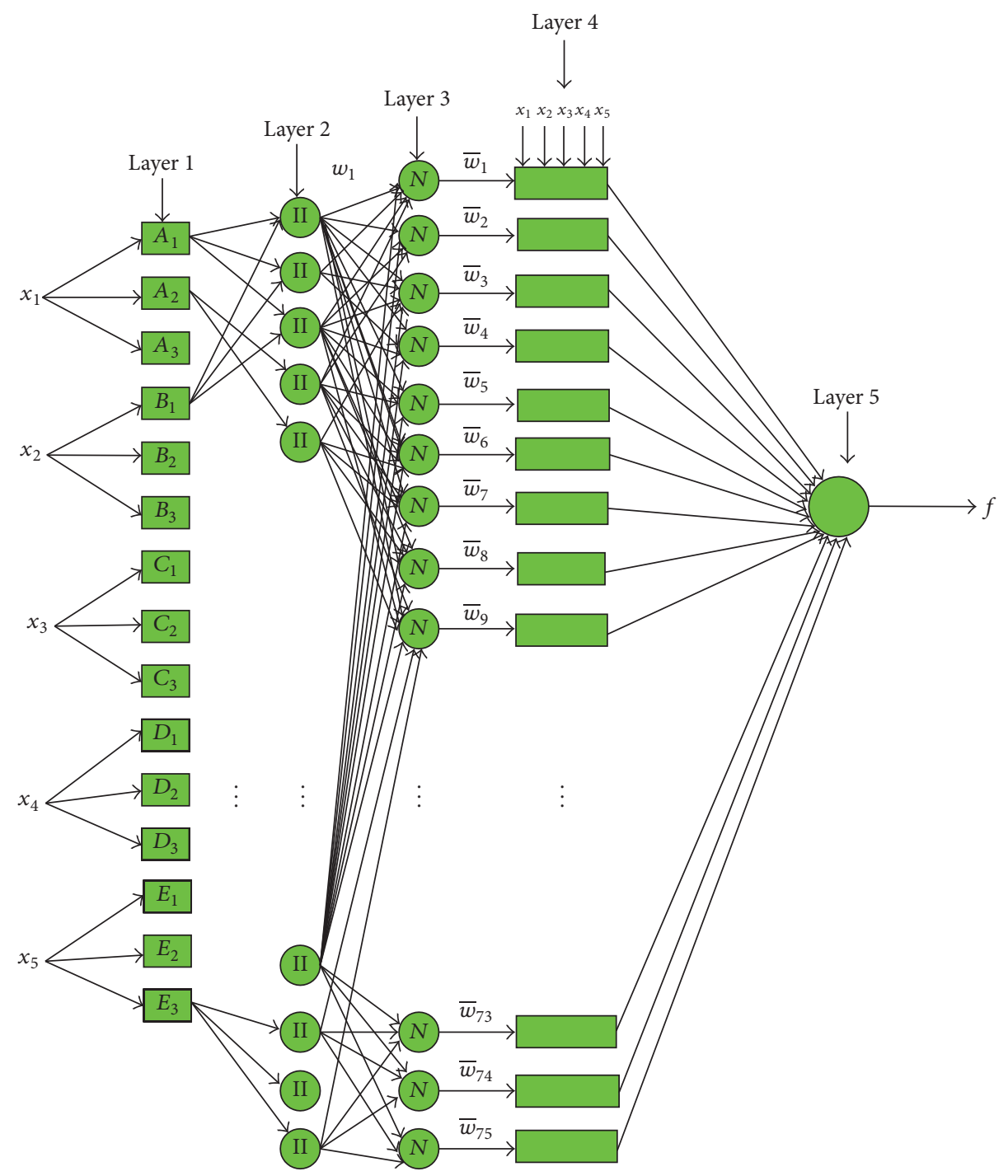

FIGURE 5: Block diagram of ANFIS used in this study.

3.3. Results and Discussion. In this study, ANFIS method was used to predict the temperature and flow field in a laboratory. The flow field showed good agreement between CFD and ANFIS results. Additionally, the difference between the values of the stream function of ANFIS and CFD was extremely small. Comparison of the calculated values with the predicted values showed that the mean variance and mean absolute error of the PMV indicator were $3.89 \times 10^{-5}$ and 0.012 , respectively. The mean variance and mean absolute error of the PPD indicator were $6.23 \times 10^{-5}$ and 0.89 , respectively. The mean variance and mean absolute error of the mean age of air indicator were $8.26 \times 10^{-3}$ and 0.15 , respectively. Almost similar values of minimum and maximum stream functions in the CFD results were obtained. The fitting curves of the calculated and predicted values are shown in Figures 6-8.

Figures 6-8 and the error analysis showed that the calculated CFD values of PMV, PPD, and the mean age of air were in agreement with the predicted values of ANFIS. Furthermore, the error was very small. The average convergence time was $15 \mathrm{~min}$. Therefore, the model established by ANFIS has high precision and good coincidence and could be a good substitute for the CFD model.

\section{Improved PSO Algorithm}

4.1. Objective Function. The main idea behind the stratified sequence method is to sort the multiobjective function according to the level of importance and then obtain the optimal solution of each single objective function. Notably, the aim of the next solution is to search within the optimal solution set obtained from the last time in the process of solving the stratified sequence method. To guarantee the existence of feasible solutions in the next solving process, the tolerance stratification sequence method is applied to broaden the feasible region by means of a tolerance value; namely, the function searches within a certain range near the optimal solution obtained in the last time, rather than being strictly restricted to the last set of optimal solutions. 


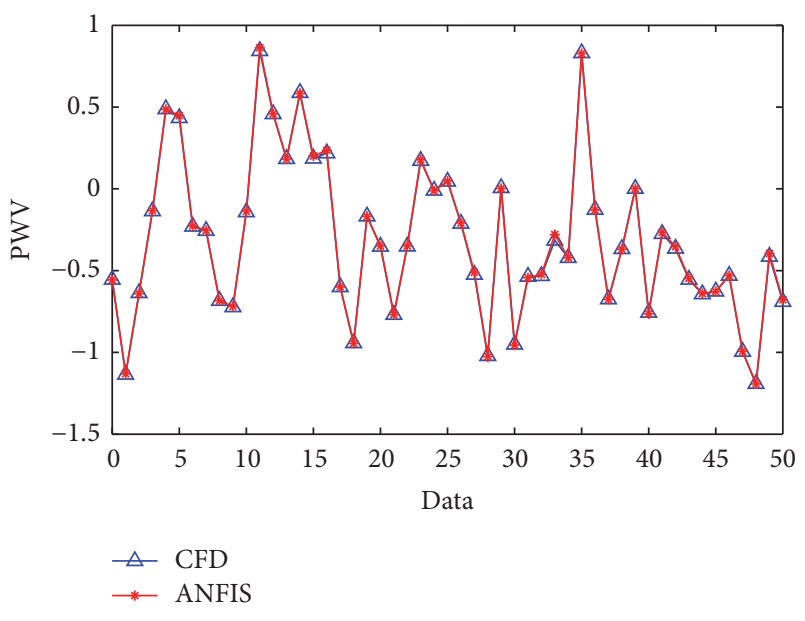

FIgURE 6: Fitting curve of PMV.

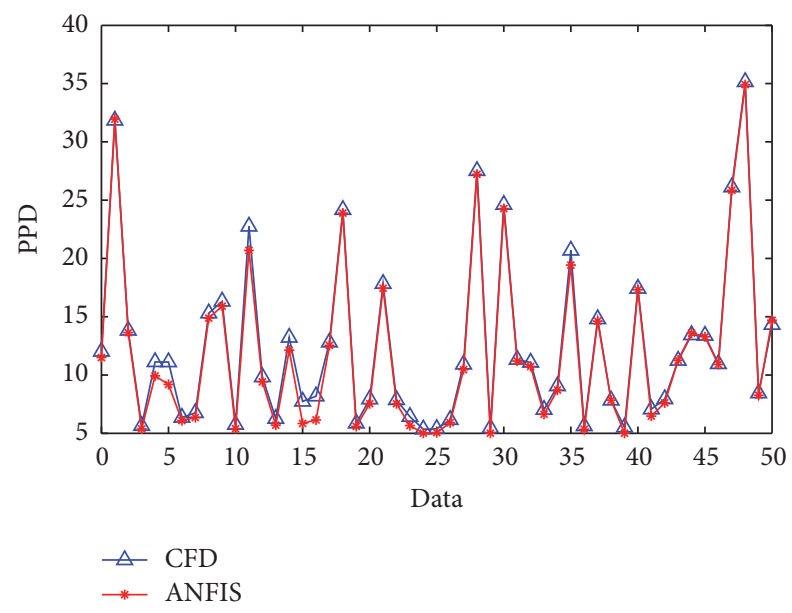

FIGURE 7: Fitting curve of PPD.

The specific implementation of the tolerance stratification sequence method is defined as follows.

We assume that $\left[f_{1}(x), f_{2}(x), \ldots, f_{p}(x)\right]$ is a multiple objective function sorted in accordance with the degree of importance. The first objective function $f_{1}(x)$ is solved as follows:

$$
\begin{array}{cc}
\min & f_{1}(x) \\
\text { s.t. } & x \in S .
\end{array}
$$

The optimal target value $f_{1}^{*}$ from the first objective function is added with a tolerance value $\varepsilon_{1}$, which is used to optimize the second objective function $f_{2}(x)$ in the broadened field of the optimal solution set. We let $S_{1}=\left\{x \mid f_{1} \leq\right.$ $\left.f_{1}^{*}+\varepsilon_{1}\right\} \cap S$. The first objective function is transformed into the constraint condition

$$
\begin{array}{ll}
\min & f_{2}(x) \\
\text { s.t. } & x \in S_{1} .
\end{array}
$$

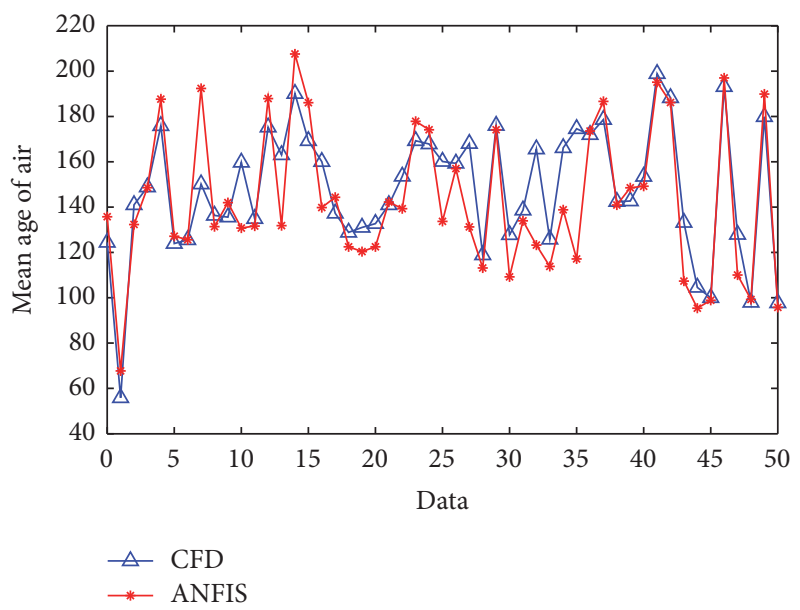

FIgURE 8: Fitting curve of the mean age of air.

Likewise

$$
\begin{array}{ll}
\min & f_{p}(x) \\
\text { s.t. } & x \in S_{p-1} .
\end{array}
$$

Therefore, $S_{p}=\left\{x \mid f_{p}(x) \leq f_{p}^{*}+\varepsilon_{p}\right\} \cap S_{p-1}$ is a set of optimal solutions in the sense of the hierarchical sequence. The tolerance stratification sequence method is introduced into the multiobjective optimization model of cutting parameters. Not only does the linear weighting method avoid determining the weight of the difficulty, but it also adds a degree of freedom in the design of the tolerance value, such that the optimization process becomes more in line with the actual production requirements. In this study, the values of PMV, PPD, and mean age of air were utilized to measure indoor thermal comfort and air quality. Thus, the objective function of PSO can be defined as

$$
\begin{array}{ll}
\min & f_{p}(\mathbf{x})=\frac{\left|G_{j}(\mathbf{x})\right|}{\left|G_{j}(\mathbf{x})_{\max }\right|} \\
\text { s.t. } & a_{i j} \leq x_{i j} \leq b_{i j} \\
& i=1,2,3,4,5 ; \\
& j=1,2,3 ; \\
& p=1,2,3,
\end{array}
$$

where $G_{j}(\mathbf{x})$ is the output; subscript $j$ pertains to different outputs that are the numerical values of PMV, PPD, and mean age of air; $\mathbf{x}_{i j}$ is the input of the neural network; subscript $i$ pertains to different outputs; $a_{i j}$ and $b_{i j}$ represent the upper and lower bounds of the input variables, respectively; and the inputs are $T, V, \operatorname{Tr}, D$, and $w$. We let $\varepsilon_{1}=1 / 3 \cdot\left(\max _{i}-\min _{i}\right)$ and $\varepsilon_{2}=1 / 3 \cdot \varepsilon_{1}$.

4.2. Optimization. Kennedy and Eberhart (1995) introduced PSO in 1995 [35]. PSO mimics the social behavior of bird 


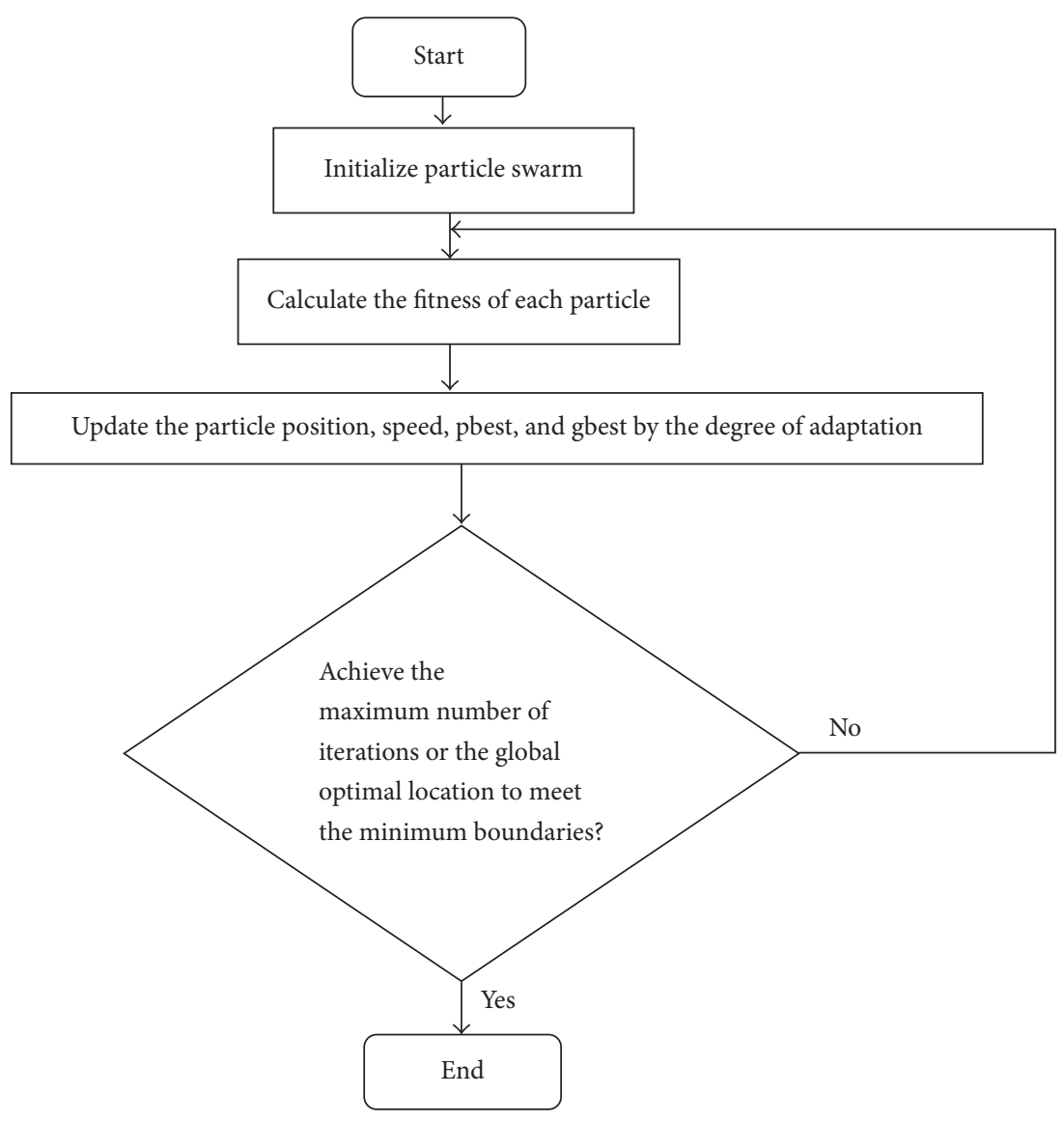

FIGURE 9: Flowchart of the PSO algorithm.

flocks or fish schools. Each time, each particle in the swarm flies to its next position at a specific speed by relying on its achieved best position and the global best position reached by any particle in the swarm. The flowchart of the PSO algorithm is illustrated in Figure 9, and the update rule of particle positions in every iteration is shown in the following two equations:

$$
\begin{aligned}
v_{i d}^{k+1}= & w v_{i d}^{k}+c_{1} \operatorname{rand}_{1}^{k}\left(\text { pbest }_{i d}^{k}-x_{i d}^{k}\right) \\
& +c_{2} \operatorname{rand}_{2}^{k}\left(\operatorname{gbest}_{i d}^{k}-x_{i d}^{k}\right), \\
x_{i d}^{k+1}= & x_{i d}^{k}+[(1+K) \text { rand }()-K] v_{i d}^{k+1} \\
& +10^{-6} \operatorname{rand}(),
\end{aligned}
$$

where $w$ is called inertia weight and is introduced to speed up the convergence of PSO; it usually has a value between $(0,1) . v_{i d}^{k}$ represents the velocity of particles. $k$ is the iteration number, which ranges within $\left(1: k_{\max }\right) . i$ is the particle number, which ranges within $(1: M) . d$ is the dimension number, which ranges within $(1: D)$. $\operatorname{rand}_{1}$ and $\operatorname{rand}_{2}$ are random numbers between $(0,1)$, and $c_{1}$ and $c_{2}$ are called accelerating coefficients. Usually, $c_{1}=c_{2}=2 . x_{i d}^{k}$ is introduced to store the current positions of every dimension of all particles. pbest (particle best) is a matrix with the same size as $x$ that stores the best position every particle reached from iteration (1: $t-1)$. gbest (global best) with size $(1, D)$ stores the best $N$ dimensional positions that give the best score by any particle from iterations $(1: t-1)$.

In this study, adaptive variation of inertia weight was employed. With the increase in the number of iterations, the inertia weight decreases, and the accuracy of the algorithm improves. The specific change formula is as follows:

$$
w=w_{\max }-\text { iter } \cdot \frac{w_{\max }-w_{\min }}{\text { iter }_{\max }}
$$

where $w_{\max }$ and $w_{\min }$ are the maximum and minimum inertia weights, respectively; iter is the current particle number of

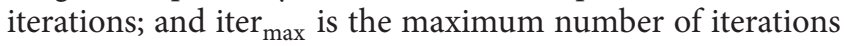
for the PSO algorithm.

The air supply parameters after optimization are illustrated in Table 3.

\section{Layout Design of the Air Conditioner and Analysis of Simulation Results}

5.1. Layout Design of the Air Conditioner. According to the optimized parameters, the optimal distance from the seats to the air supply outlet is $3.6 \mathrm{~m}$. Thus, the following method was adopted to determine the size and location of the air 
TABLE 3: Three different evaluation indicators to achieve optimal air conditioning parameters.

\begin{tabular}{|c|c|c|c|c|}
\hline Evaluation indicators & Velocity $(\mathrm{m} / \mathrm{s})$ & Temperature $\left({ }^{\circ} \mathrm{C}\right)$ & Relative humidity (\%) & Distance $(\mathrm{m})$ \\
\hline PMV & 0.42 & 23.48 & 49.39 & 5.70 \\
\hline PPD & 0.42 & 21.69 & 58.48 & 4.20 \\
\hline Mean age of air & 0.43 & 19.87 & 63.19 & 3.60 \\
\hline
\end{tabular}

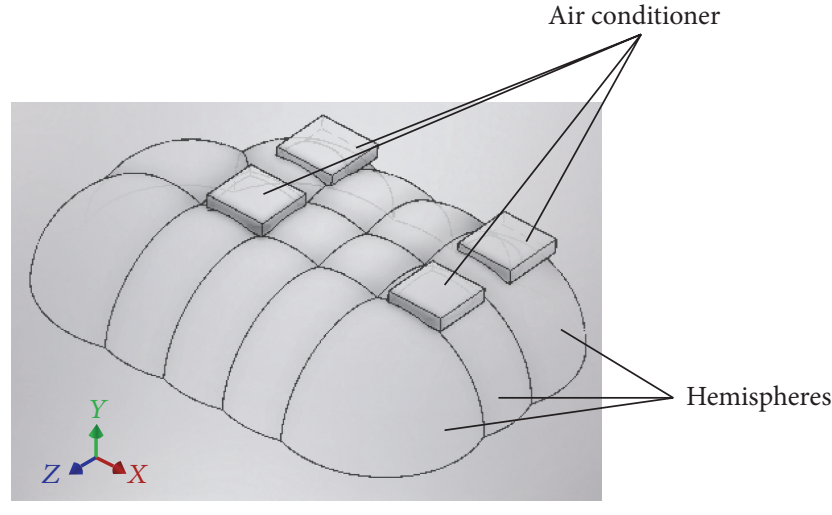

FIGURE 10: Location of the air conditioner.

conditioner. First, the structure of the air supply was set to the shape of a cube, as shown in Figure 11. Second, the sphere centers $R_{i}(i=1,2, \ldots, 14)$ were set to the height of the human chest ( $X Z$ section of $Y=1.1 \mathrm{~m}$ height). Third, a hemisphere with the radius of $3.6 \mathrm{~m}$ was drawn, and the location and size of the air conditioner were defined at the intersection of adjacent hemispheres. The location of the air conditioner is shown in Figure 10. The final size of the air conditioner was $1.2 \mathrm{~m} \times 1.2 \mathrm{~m} \times 0.5 \mathrm{~m}$ (length $\times$ width $\times$ height).

5.2. Analysis of CFD Simulation. The optimized results showed that the air supply's position in the model needs to be rearranged. The top distribution of the four cube air supply outlets was adopted in place of the original one. Then, the optimal distance from each air supply outlet to the surrounding seats and the optimized indoor control parameters were employed. For example, the temperature of the air supply outlet of the air conditioner was $19.67^{\circ} \mathrm{C}$, indoor relative humidity was adjusted to $63.19 \%$, and the air velocity was $0.43 \mathrm{~m} / \mathrm{s}$. The redesigned distribution of the indoor air conditioning is shown in Figure 11, and the distribution of PMV, PPD, and mean age of air was obtained when the indoor condition was stabilized, as presented in Figures 12-14.

The distribution of the PMV values was even, as depicted in Figure 12. In this condition, people normally experience thermal comfort. When the PMV values ranged from -0.5 to 0 , the evaluation of thermal comfort was "moderate." In the seat near the return air vent, the PMV values were around -1.5 , and the evaluation of thermal comfort was "slightly cold." In short, when the evaluation of the indoor environment's comfort is "moderate," people experience good thermal comfort. Compared with that in Figure 2, the optimized value of PMV is 0 near the seats around people, which represents a "moderate" feeling of comfort.

The distribution of the PPD values was even, as shown in Figure 13. In this condition, people normally have a satisfactory sense of thermal comfort because the PPD values are about $10 \%$. In the seat near the return air vent, the PPD values were between $30 \%$ and $55 \%$, which shows that the evaluation of thermal comfort is rather low. Overall, people are satisfied with the thermal environment. Compared with those in Figure 3, the optimized values of PPD are about 10\%, which means that the satisfaction degree of people is high.

The values of air age in the room ranged from 50 to $95 \mathrm{~s}$, and the distribution was balanced as shown in Figure 14. The values of air age were between 50 and $70 \mathrm{~s}$, which shows that the effect of ventilation was good. Compared with those in Figure 4, the values of air age inside the room were smaller, and air circulation was better.

Overall, as the distribution of PMV, PPD, and air age becomes increasingly balanced, the feeling of thermal comfort and the satisfaction degree of persons indoors obviously improve. The optimized values of air age were smaller than those before, and indoor air circulation was enhanced. Compared with the original data and contour images, we conclude that the optimized indoor air quality was significantly enhanced, and people in the laboratory can enjoy a comfortable environment, which in turn can improve their learning efficiency. Compared with the local air supply structure in the study of Skovgaard and Nielsen [8], the structure of air supply in the current study has a shape of a cube, and the values of PMV range from -0.5 to 0 with an even distribution near the seats. The evaluation of thermal comfort in the room is "moderate." Compared with structure of the upper air supply and downside air outlet of the air conditioning system employed by Riederer et al. [9], the structure in the present work can provide improved ventilation with the values of air age ranging from 50 to $70 \mathrm{~s}$.

5.3. Validation of Optimal Solutions. Based on the above optimization work, the method of combining ANFIS with PSO was applied to verify the accuracy and preponderance of the optimal solutions. For validation purposes, we first used the office model obtained by $\mathrm{Xu}$ et al. [28] to simulate the indoor thermal environment via CFD. Second, the approach of ANFIS-PSO was used to optimize the indoor control variables. Finally, the index of thermal comfort obtained by the present work was compared with the experimental data obtained by $\mathrm{Xu}$ et al. [28].

The control variables after optimization are illustrated in Table 4.

In the present study, several samples were obtained after the indoor climate condition stabilized. Figure 15 shows that 


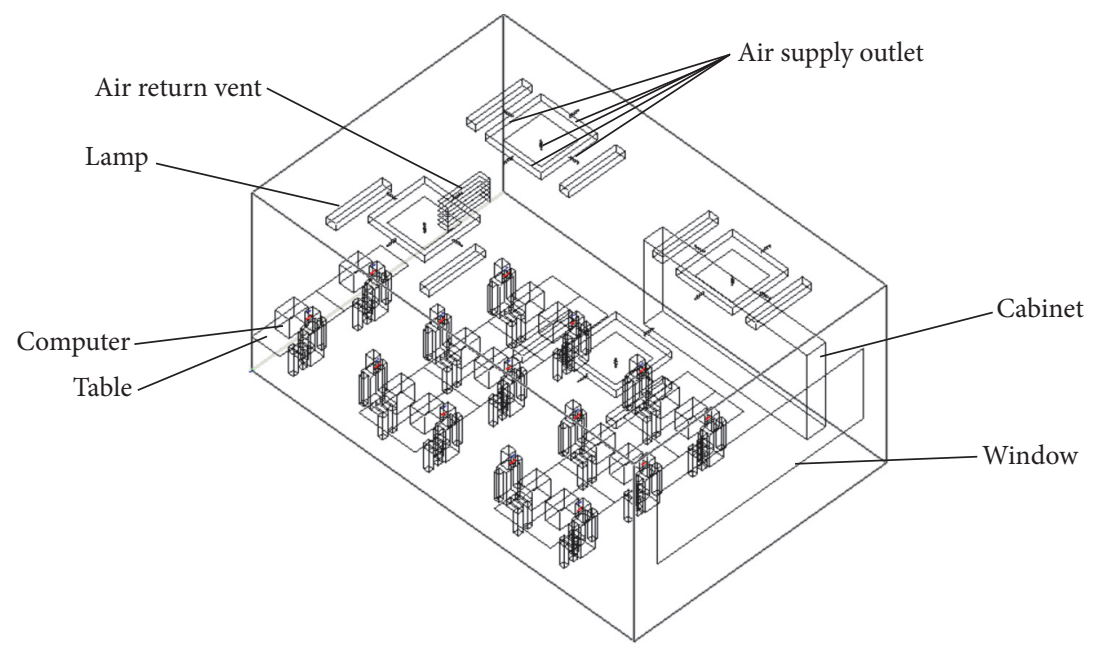

FIgURE 11: Optimized physical model.
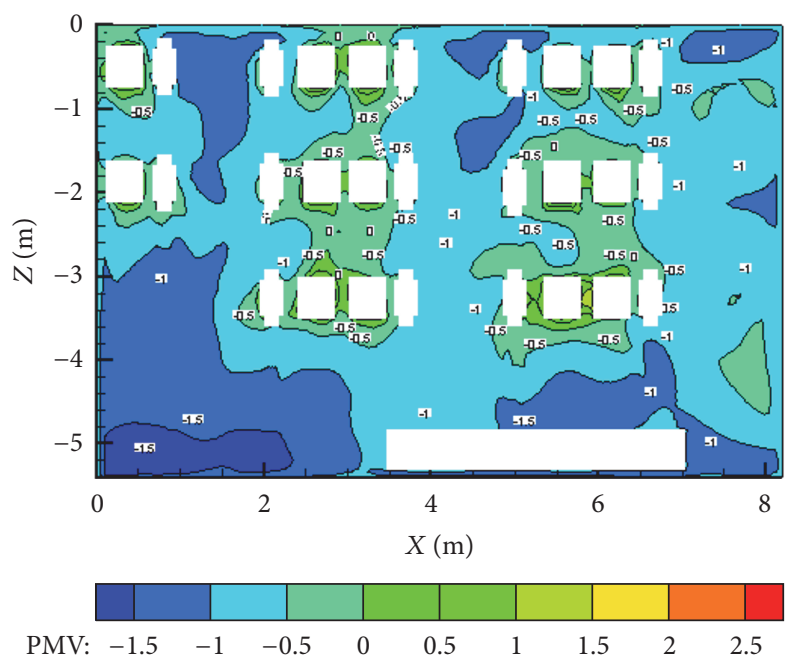

FIGURE 12: Distribution of the optimized PMV values.

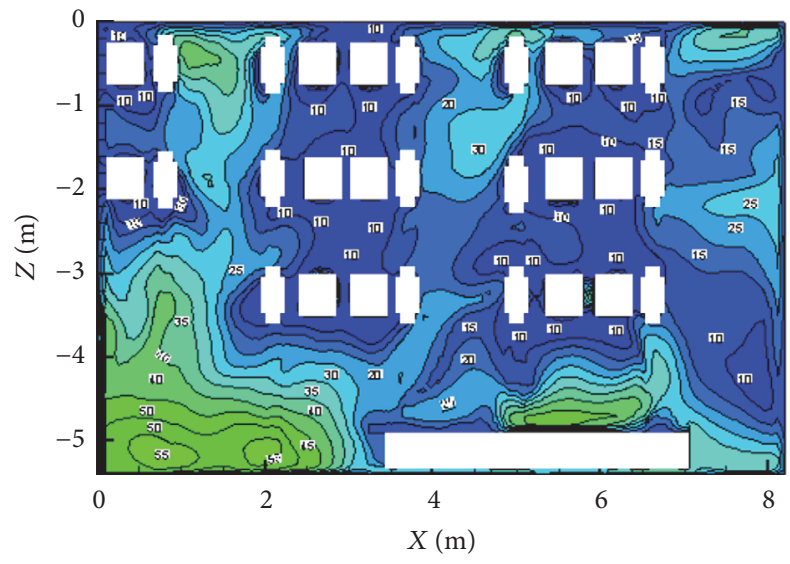

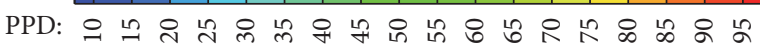

FIGURE 13: Distribution of the optimized PPD values.
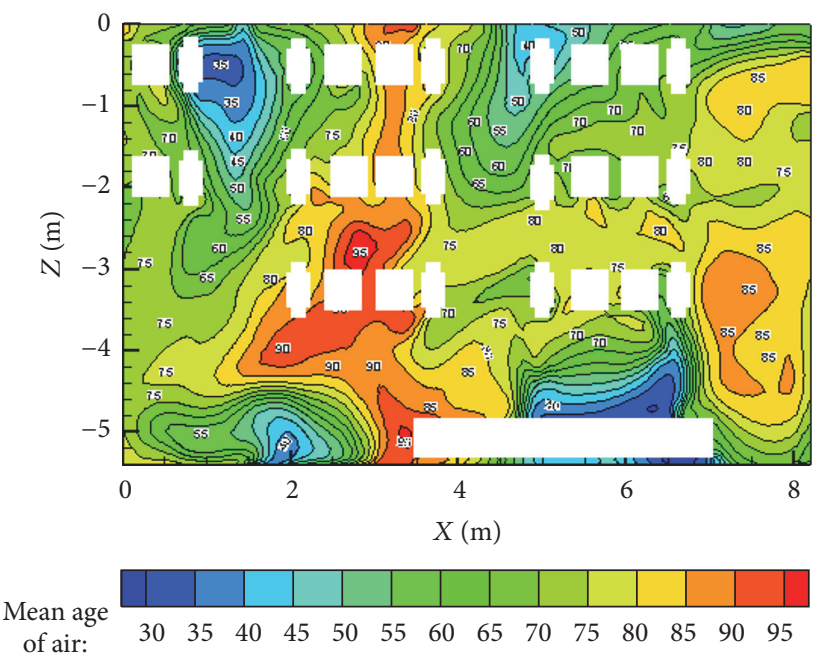

FIGURE 14: Distribution of the optimized values of air age.

TABLE 4: Comparison of the optimal variables in the present work with those in Xu et al. [28].

\begin{tabular}{lcccc}
\hline $\begin{array}{l}\text { Control } \\
\text { variables }\end{array}$ & $\begin{array}{c}\text { Velocity } \\
(\mathrm{m} / \mathrm{s})\end{array}$ & $\begin{array}{c}\text { Temperature } \\
\left({ }^{\circ} \mathrm{C}\right)\end{array}$ & $\begin{array}{c}\text { Relative humidity } \\
(\%)\end{array}$ & $\begin{array}{c}\text { Distance } \\
(\mathrm{m})\end{array}$ \\
\hline $\begin{array}{l}\text { Present } \\
\text { work }\end{array}$ & 0.42 & 23 & 63 & 3.2 \\
$\begin{array}{l}\text { Xu et al. } \\
{[28]}\end{array}$ & 0.26 & 22 & 67 & 2.9 \\
\hline
\end{tabular}

the temperature ranged between $26^{\circ} \mathrm{C}$ and $27.3^{\circ} \mathrm{C}$. The indoor thermal parameters in the office were in rough agreement with the experimental data obtained by Xu et al. [28] shown in Figure 15. Furthermore, compared with the optimal results of $\mathrm{Xu}$ et al. [28], the thermal state of the office is improved, and the distribution of temperature in corners is more uniform (Figure 16). 


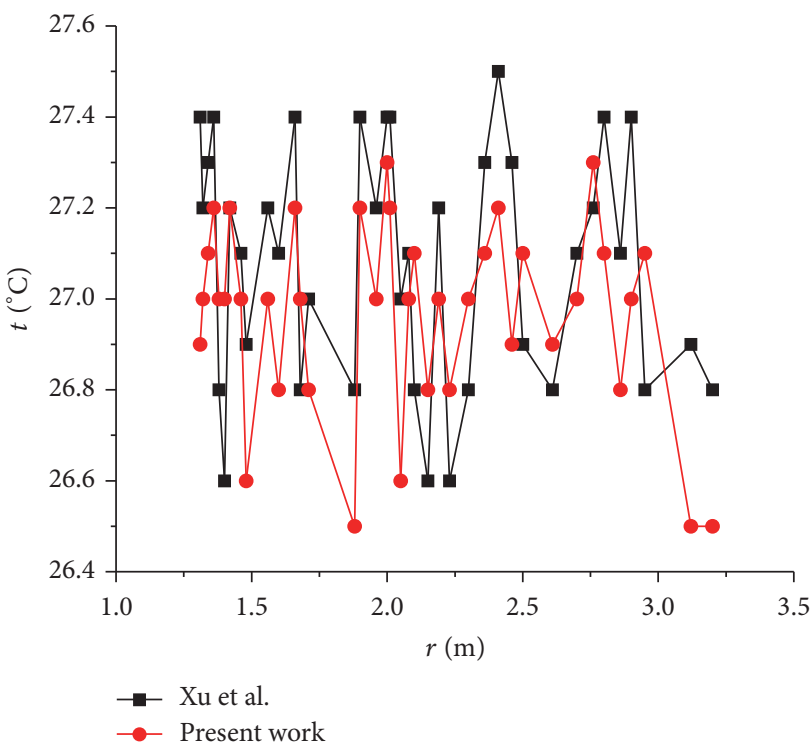

(a) Comparison of temperature

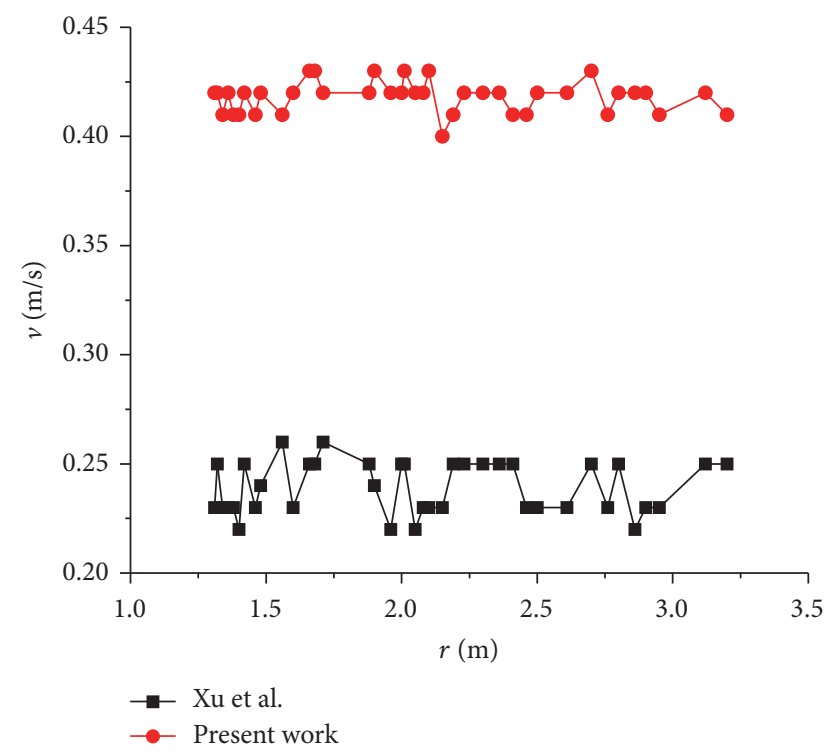

(b) Comparison of velocity

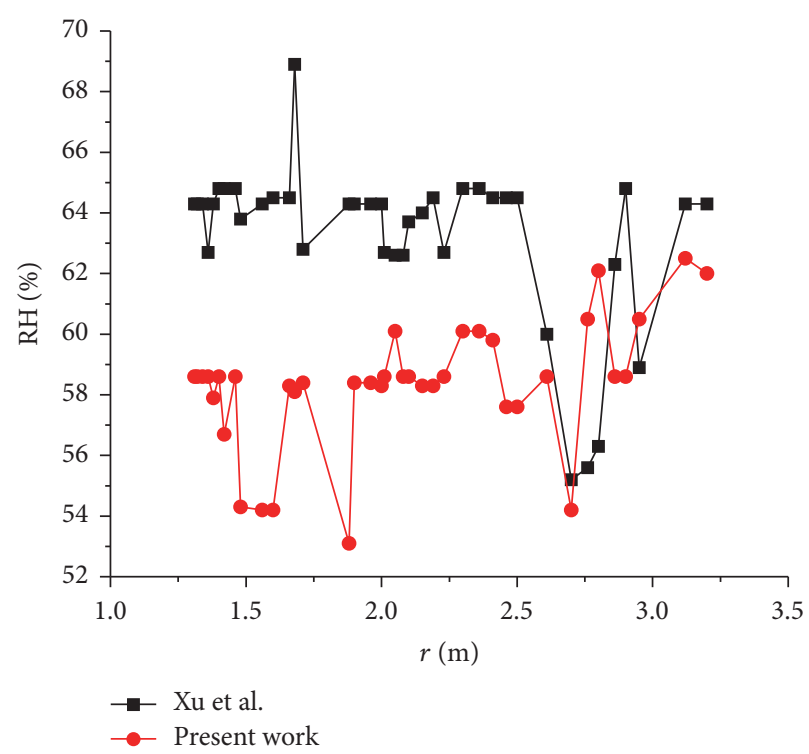

(c) Comparison of relative humidity

FIgURE 15: Comparisons of $T, V$, and relative humidity between the method of ANFIS-PSO and that in Xu et al. [28].

Accordingly, we conclude that the presented numerical procedure is a reliable method of predicting the flow and heat transfer in an air-conditioned room.

\section{Conclusions}

In this study, ANFIS modeling and the improved PSO algorithm were combined to improve indoor thermal comfort parameters. The following conclusions were obtained.

(1) The proposed methodology is an integrated ANFISPSO approach developed to optimize air conditioner design in terms of thermal comfort and indoor air quality. The advantage of this integration relies on the reliability of the prediction of indoor thermal and environmental conditions provided by the CFD model. Effect evaluation of the ANFIS model indicated that the ANFIS model can exactly describe the relationship between indoor thermal comfort indicators (PMV, PPD, and age of air) and several factors pertaining to air conditioning (air temperature, relative humidity, indoor radiation temperature, air velocity, and distance from the air supply outlet to people). The ANFIS model can optimize the mathematical model, and the convergence time is about 40 min. Hence, the ANFIS model can replace the CFD model, whose convergence time reaches $12 \mathrm{~h}$. The former can significantly increase the convergence speed under the premise of ensuring accuracy.

(2) With the improved PSO algorithm and the stratified sequence method, thermal comfort indicators PMV, PPD, 


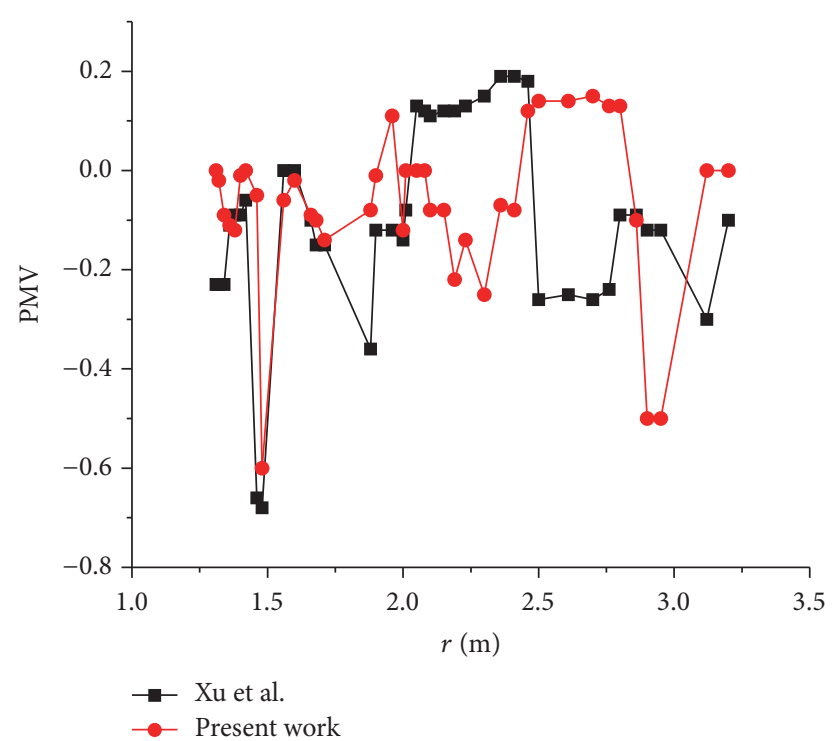

FIGURE 16: Comparison of the index of PMV between the method of ANFIS-PSO and that in Xu et al. [28].

and age of air were optimized layer by layer to obtain the optimal air conditioning parameters and installation distance. For example, air temperature was $19.87^{\circ} \mathrm{C}$, air velocity was $0.43 \mathrm{~m} / \mathrm{s}$, and the optimal distance from the air supply outlet to people was $3.60 \mathrm{~m}$.

(3) The air conditioning arrangement of the cube air supply mode can be utilized to solve the problems of high temperature and poor ventilation in the local area. The distribution of PMV in the room was optimized from -1.5 to 1.5 to -0.5 to 0 . The PPD values were optimized from $60 \%$ to $80 \%$ to about $10 \%$ and the age of air from $60 \mathrm{~s}$ to $120 \mathrm{~s}$ to $50 \mathrm{~s}$ to $70 \mathrm{~s}$. The optimized results showed that the level of thermal comfort was "moderate," and the effectiveness of ventilation was good. This condition means that people are highly satisfied with the indoor thermal environment.

This study focused only on one room in the university, and several factors, such as noise and pollution, were not examined. In the future, other factors should be considered through experimentation.

\section{Conflicts of Interest}

The authors declare that they have no competing interests and there are no conflicts of interest regarding the publication of this paper. And all authors are not in dispute.

\section{Acknowledgments}

This work was supported by the National Key Research and Development Program of China (no. 2016YFB0601101).

\section{References}

[1] C. H. Zhu, Study on the Evaluation of the Indoor Environment and the Grey Theory, Hunan University, 2012.
[2] L. Mora, A. J. Gadgil, and E. Wurtz, "Comparing zonal and CFD model predictions of isothermal indoor airflows to experimental data," Indoor Air, vol. 13, no. 2, pp. 77-85, 2003.

[3] A. Karimipour, M. H. Esfe, M. R. Safaei, D. T. Semiromi, S. Jafari, and S. N. Kazi, "Mixed convection of copper-water nanofluid in a shallow inclined lid driven cavity using the lattice Boltzmann method," Physica A: Statistical Mechanics and Its Applications, vol. 402, pp. 150-168, 2014.

[4] A. Karimipour, A. Hossein Nezhad, A. D’Orazio, M. Hemmat Esfe, M. R. Safaei, and E. Shirani, "Simulation of copper-water nanofluid in a microchannel in slip flow regime using the lattice Boltzmann method," European Journal of Mechanics, B/Fluids, vol. 49, pp. 89-99, 2015.

[5] M. R. Safaei, O. Mahian, F. Garoosi et al., "Investigation of micro- and nanosized particle erosion in a 90。 pipe bend using a two-phase discrete phase model," Scientific World Journal, vol. 2014, Article ID 740578, 12 pages, 2014.

[6] M. H. Esfe, A. A. A. Arani, A. Karimipour, and S. S. M. Esforjani, "Numerical simulation of natural convection around an obstacle placed in an enclosure filled with different types of nanofluids," Heat Transfer Research, vol. 45, no. 3, pp. 279-292, 2014.

[7] A. Karimipour, M. Afrand, M. Akbari, and M. R. Safaei, "Simulation of fluid flow and heat transfer in the inclined enclosure," International Journal of Mechanical and Aerospace Engineering, vol. 6, pp. 86-91, 2012.

[8] M. Skovgaard and P. V. Nielsen, Modelling Complex Inlet Geometries in CFD, Aalborg Universitetsforlag, 1991.

[9] P. Riederer, D. Marchio, and J. C. Visier, "Influence of sensor position in building thermal control: criteria for zone models," Energy and Buildings, vol. 34, no. 8, pp. 785-798, 2002.

[10] X. Peng and A. H. C. Van Paassen, "A state space model for predicting and controlling the temperature responses of indoor air zones," Energy and Buildings, vol. 28, no. 2, pp. 197-203, 1998.

[11] A. C. Megri and F. Haghighat, "Zonal modeling for simulating indoor environment of buildings: review, recent developments, and applications," HVAC and R Research, vol. 13, no. 6, pp. 887905, 2007.

[12] L.-S. Cao and J. Zhu, "Prediction of submarine hydrodynamics using CFD-based calculations and RBF neural network," Journal of Ship Mechanics, vol. 18, no. 3, pp. 221-230, 2014.

[13] G. Krauss, J. I. Kindangen, and P. Depecker, "Using artificial neural networks to predict interior velocity coefficients," Building and Environment, vol. 32, no. 4, pp. 295-303, 1997.

[14] W. Xu, X. G. Chen, and H. X. Peng, "Optimization of the control variables of indoor thermal comfort based on genetic algorithm and neural network," Transaction of Beijing Institute of Technology, vol. 30, no. 2, pp. 240-244, 2010.

[15] G. M. Stavrakakis, D. P. Karadimou, P. L. Zervas, H. Sarimveis, and N. C. Markatos, "Selection of window sizes for optimizing occupational comfort and hygiene based on computational fluid dynamics and neural networks," Building and Environment, vol. 46, no. 2, pp. 298-314, 2011.

[16] M. Buragohain and C. Mahanta, "A novel approach for ANFIS modelling based on full factorial design," Applied Soft Computing, vol. 8, no. 1, pp. 609-625, 2008.

[17] B. Sun, N. G. Jiang, K. Han et al., "The optimal design method using CFD combined with genetic algorithm for indoor thermal comfort," Journal of Chongqing Jianzhu University, S2, pp. 119122, 2011. 
[18] Q. L. Luan and H. B. Lu, "Research of intrusion detection based on neural network optimized by adaptive genetic algorithm," Computer Engineering and Design, 2008.

[19] Q. He, "Research on the development of artificial intelligence technology," Modern Telecommunication Technology, vol. 2, pp. 18-21, 2016.

[20] I. Dis, Moderate Thermal Environments-Determination of the $P M V$ and PPD Indices and Specification of the Conditions for Thermal Comfort, International Standards Organization, Geneva, Switzerland, 1984.

[21] P. O. Fanger, A. K. Melikov, H. Hanzawa, and J. Ring, "Air turbulence and sensation of draught," Energy and Buildings, vol. 12, no. 1, pp. 21-39, 1988.

[22] B. Zhao, D. L. Li, X. T. Li et al., "Error pretreatment method for numerical simulation of indoor air flow," Journal of Tsinghua University (Natural Science Edition), vol. 10, pp. 114-117, 2001.

[23] L. Zhou and F. Haghighat, "Optimization of ventilation system design and operation in office environment, part I: methodology," Building and Environment, vol. 44, no. 4, pp. 651-656, 2009.

[24] R. Z. Freire, G. H. C. Oliveira, and N. Mendes, "Predictive controllers for thermal comfort optimization and energy savings," Energy and Buildings, vol. 40, no. 7, pp. 1353-1365, 2008.

[25] T. Kim, D. Song, S. Kato, and S. Murakami, “Two-step optimal design method using genetic algorithms and CFD-coupled simulation for indoor thermal environments," Applied Thermal Engineering, vol. 27, no. 1, pp. 3-11, 2007.

[26] D.-C. Ma, Y.-B. Diao, Y.-Z. Guo et al., "A novel method to predict protein-protein interactions based on the information of protein-protein interaction networks and protein sequence," Protein and Peptide Letters, vol. 18, no. 9, pp. 906-911, 2011.

[27] H. H. H. Homeier, "A hierarchically consistent, iterative sequence transformation," Numerical Algorithms, vol. 8, no. 1, pp. 47-81, 1994.

[28] W. Xu, X.-G. Chen, J. Zhao, and H. Hu, “Thermal comfort in offices: comfort values and optimization of indoor control variables," Journal of Beijing Institute of Technology, vol. 20, no. 1, pp. 123-128, 2011.

[29] J. H. Huang and H. Zhang, Human and Thermal Environment, Science Press, Beijing, China, 2011.

[30] Y. Z. Ji, K. Gao, X. J. Wang et al., "Study on the influence of air velocity on thermal comfort of human body," Journal of Lanzhou University, vol. 2, pp. 95-99, 2003.

[31] T. Bedford, Basic Principles of Ventilation and Heating, Lewis, London, UK, 1998.

[32] R. Nevins, R. R. Gonzalez, Y. Nishi et al., "Effect of change in ambient temperature and level of humidity on comfort and thermal sensation," ASHRAE Transactions, vol. 81, no. 2, pp. 6477, 1975.

[33] S. V. Pascal and Z. Z. Zhang, Numerical Calculation of Heat Transfer and Fluid, Science Press, Beijing, China, 1984.

[34] S. Shamshirband, A. Malvandi, A. Karimipour et al., "Performance investigation of micro- and nano-sized particle erosion in a 90॰ elbow using an ANFIS model," Powder Technology, vol. 284, pp. 336-343, 2015.

[35] C. Y. Zhang, Research of Fuzzy Neural Network Based on Improved PSO Algorithm, Harbin University of Science and Technology, 2014. 


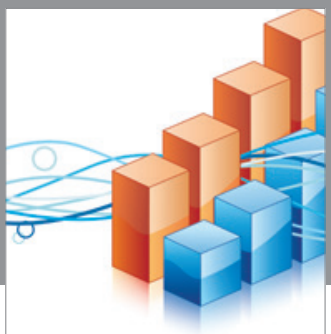

Advances in

Operations Research

vatem alat4

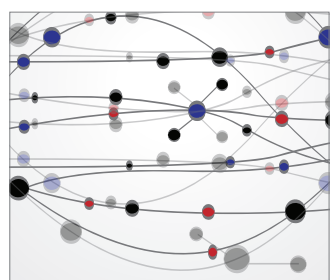

\section{The Scientific} World Journal
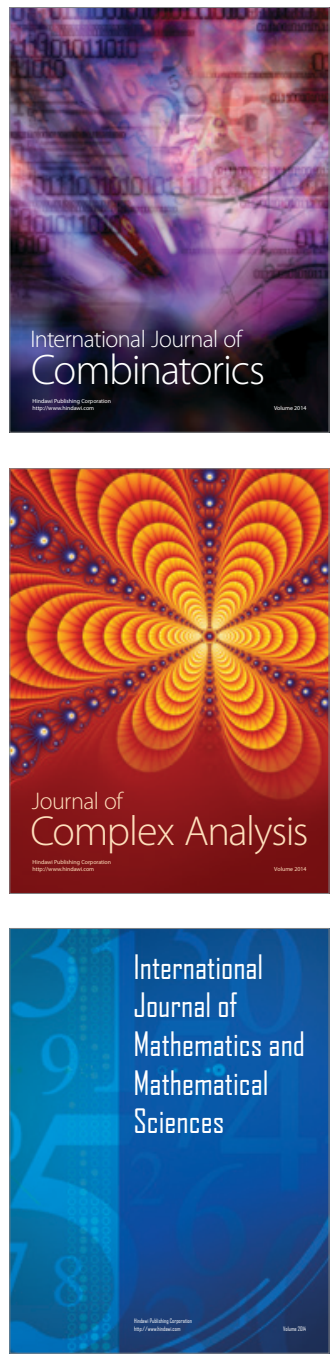
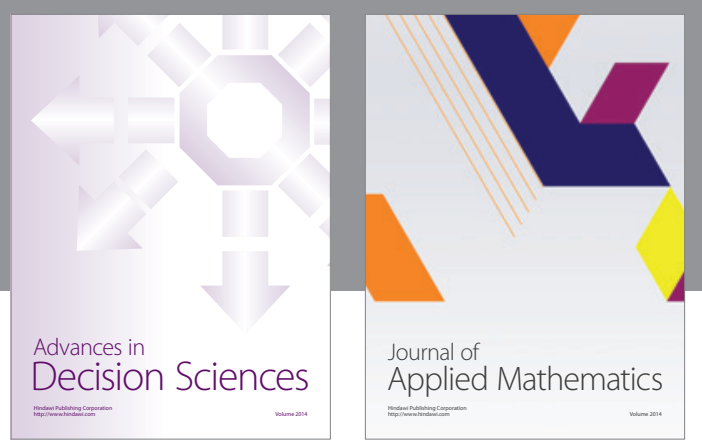

Algebra

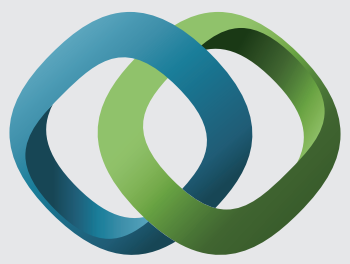

\section{Hindawi}

Submit your manuscripts at

https://www.hindawi.com
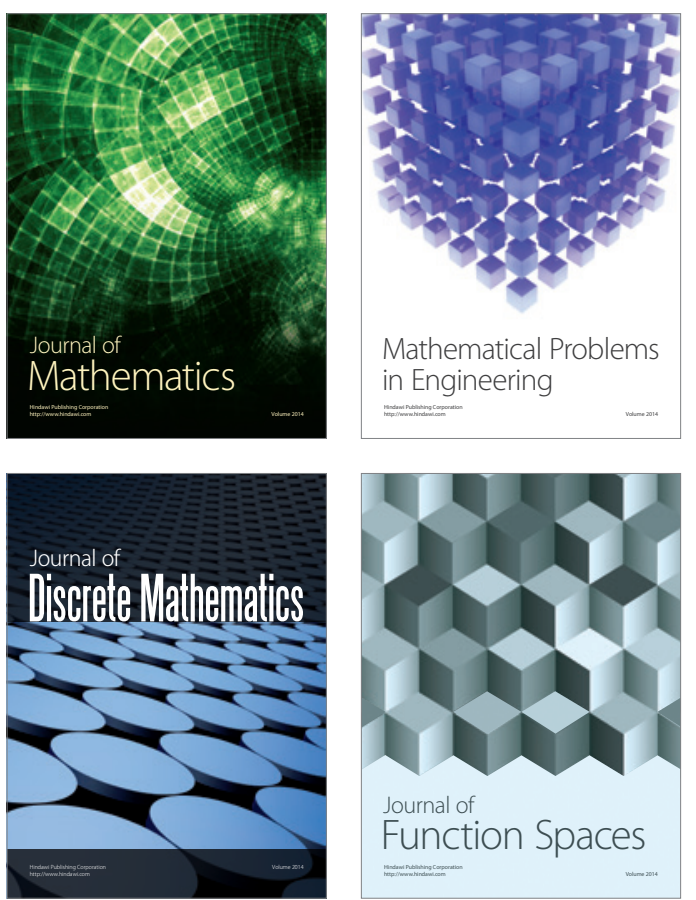

Mathematical Problems in Engineering
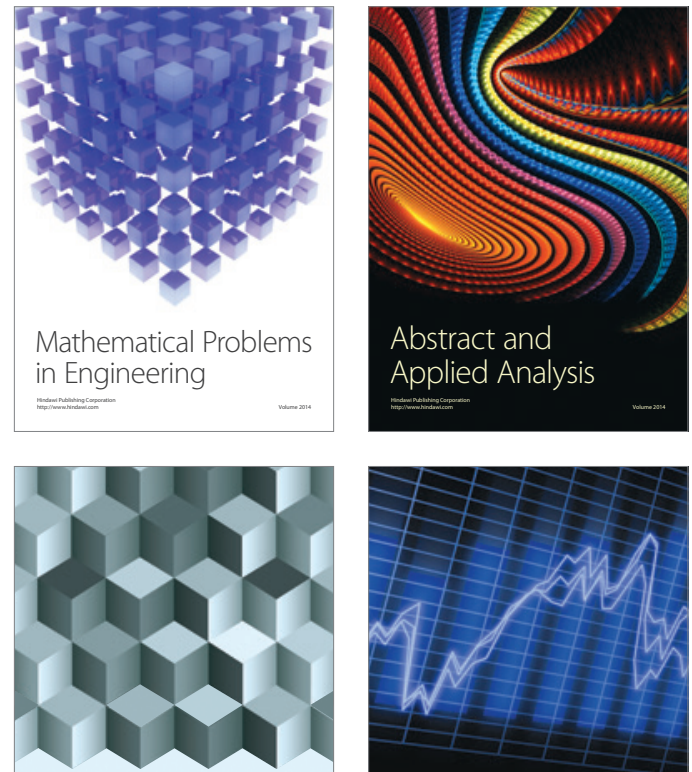

Journal of

Function Spaces

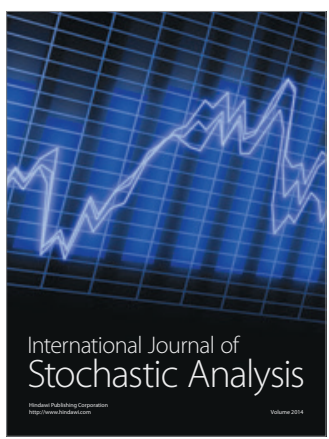

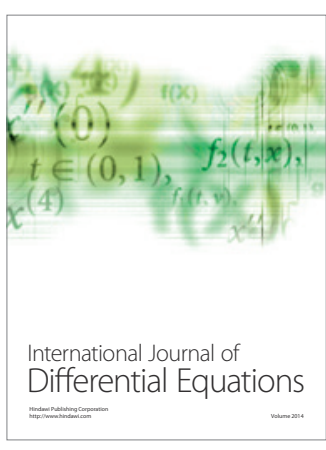
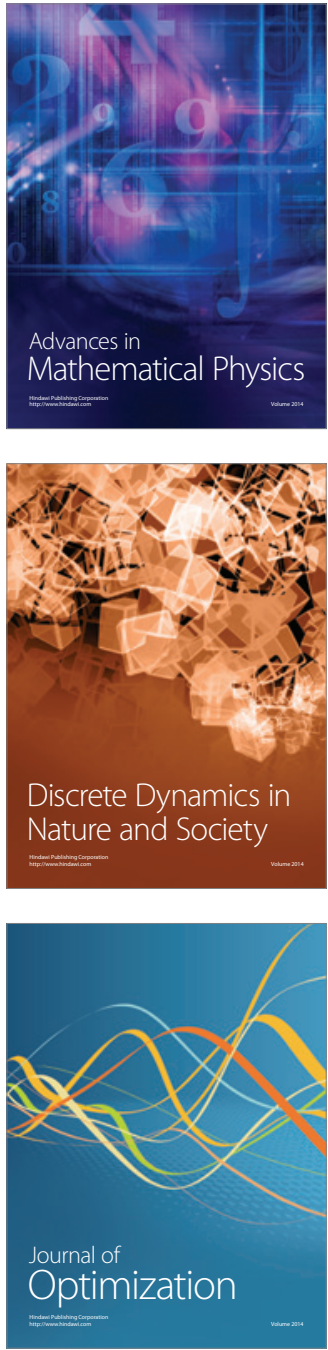